\title{
Facebook Addiction among Malaysian Students
}

\author{
Hosein Jafarkarimi, Alex Tze Hiang Sim, Robab Saadatdoost, and Jee Mei Hee
}

\begin{abstract}
In recent years, Social Networking Sites (SNSs) have become a major communication vehicle in all societies. Facebook has become the most popular social networking site with more than 2.2 billion users. The pleasure that Facebook has brought has led to some addictive behavior among its users. This study employed the Bergen Facebook Addiction Scale to investigate Facebook addiction among students. In this study, we selected a sample of 441 students in Universiti Teknologi Malaysia as respondents. Results show that $47 \%$ of the participants were addicted to Facebook. This ratio is almost the same among postgraduate and undergraduate students, and interestingly, among Malaysian and non-Malaysian. Much speculated factors such as religion, level of income, ego strength and locus of control do not show significant influence on the risk of Facebook addiction. Lastly, the results suggest that as people spend more time on Facebook, there is a greater chance of addiction.
\end{abstract}

Index Terms-Facebook addiction, social networking sites, students.

\section{INTRODUCTION}

Internet-mediated interaction showed negative effects on wellbeing. Different researches have shown negative effect of heavy SNS use and depression [1], anxiety [2], histrionic personality, [3] and addiction and dependency [4]. Having this in mind, the widespread use of SNSs and particularly Facebook [4] among youths should raise some crucial attention. Even though it is still too early to see the whole negative impact of Facebook addiction in our societies and there is still more to come.

In recent years, it has been recognized that the impact of Information Technology (IT) addiction has become considerably more important. Many researches have been conducted on this topic (e.g. [5]-[7]). It became a global concern and considered as a health issue [8]. Information Technology addiction took different forms including mobile phone addiction [9], online sex addiction [10], [11], computer games addiction [12], online shopping and gambling addiction [13], Internet addiction [14]. A more recent topic in the field of IT and Internet addiction is Social Networking Sites (SNS) addiction [15]. The most popular SNS in

Manuscript received September 8, 2014; revised December 23, 2014 This work was supported in part by research university grant (vot. 4F441) from Universiti Teknologi Malaysia.

H. Jafarkarimi is with Univeristi Teknologi Malaysia. He is also with Department of Computer, Damavand Branch, Islamic Azad University, Damavand, Iran (e-mail: hoseinkarimi@gmail.com).

A. Sim is with the Department of Information Systems, Universiti Teknologi Malaysia, Malaysia.

R. Saadatdoost is with the Department of Computer and Information Technology, Parand Branch, Islamic Azad University, Parand, Iran.

J. Hee is with the Department of Educational Foundation and Social Science, Faculty of Education, Universiti Teknologi Malaysia, Malaysia.
Malaysia is Facebook with more than 13 million Malaysian users [16]. This research aims to investigate the trend of Facebook addiction among students using Bergen Facebook Addiction Scale (BFAS) [17] tool.

\section{BACKGROUND OF STUDY}

Addiction in general is defined as "the condition of being unable to stop taking or doing something harmful [18]. Different ethics' schools of thought believe that individuals are rational beings who have the ability to use their critical judgment to manage their lives [19]. Kant believed that whatever controlled an individual's mind and stopped him or her from using judgment is a vice [20]. Hence, addiction which is a desire that control your mind can be considered as a vice and is unethical.

In 1970, two individuals predicted that the joy which will be brought by computers will be extremely captivating and the attraction of computers will be far greater than any other hobby [21]. In 1976, Joseph Weizenbaum [22] claimed that feelings of power and freedom attract computer programmers to their machines. He believed the reason behind this feeling is that instead of physical objects, programmers deal with bits and they are free to design their imagination and the machine will execute their orders without question. This may lead them to a compulsion to program. Weizenbaum's idea was later echoed by different scholars and became a topic in both fields of Psychology and Computer [23].

Currently, some people spend between 40-80 hours online each week which has different harmful consequences. In addition to some physical issues like eyestrain, back strain and carpal tunnel syndrome, it can affect the relationships with friends and family members [24]. In his study on computer addiction, Shotton [25] observed that those who are dependent on computers from a very early age show little or no satisfaction in interacting with others and their attitude toward other people is significantly negative. He states that:

"Attending school apparently proved difficult for most of the Dependents. They did not mix well and felt themselves to be different from the other children, often being ostracized by their peers because of their intellectual interests and abilities. Neither were they particularly popular with their teachers. They found formal teaching methods stultifying, preferring to undertake their own research into a subject." [25].

In recent years, the impact of technology addiction has become more and more important. Many researches have been done on it and it has become a global concern and is now considered a health issue. For instance, Internet addiction was suggested to be considered as a cause of mental disorder [26] and has been included in "Diagnostic and Statistical Manual of Mental Disorder" [27]. 
According to a survey done by global insurer AIA Group Ltd in 2013, although internet diffusion in Malaysia is not as high as other countries in the region, $73 \%$ of adults who have been interviewed in Malaysia agreed that their online activities including social networking are becoming addictive. This places Malaysia in the highest rank among countries in the region. This case is not limited only to adults; another study which was done on a random sample of Malaysian youth suggests that a great proportion (64\%) of studied individuals considered themselves as internet addicts [28]. This is a new threat to healthy living style and it can be said that Malaysian internet users are at a high risk of being Internet addicts. This issue needs action to be taken to overcome the problem [29].

\section{METHOD}

\section{A. Participants}

Four hundred and fifty nine students from Universiti Teknologi Malaysia participated in this study. The sample was selected in convenient basis in which all the respondents were SNS users. After removing eighteen incomplete or incorrect questionnaires, sample consisted of $51 \%$ male and $49 \%$ female aged from 17 to 48 (Mean 24.8 years, SD 5.41). Among them, 58\% were undergraduate students and $42 \%$ were postgraduate students.

\section{B. Design and Procedure}

As discussed before, the BFAS were used in this study to measure Facebook addiction. This scale contains six questions on 5-Likert Scale basis each reflecting a dimension of six basic components of addiction proposed by Brown [30] and Griffiths [31] (salience, mood modification, tolerance, withdrawal, conflict and relapse). BFAS asks the respondents to answer how often during last year they have experienced the following: "1. Spent a lot of time thinking about Facebook or planned use of Facebook", "2. Felt an urge to use Facebook more and more, "3. Used Facebook in order to forget about personal problems", "4. Tried to cut down on the use of Facebook without success", "5. Become restless or troubled if you have been prohibited from using Facebook." And "6.Used Facebook so much that it has had a negative impact on your job/studies." Respondents have 5 options ranging from very rarely to very often and need to pick their answers among them.

In addition to this scale, Barron's Ego strength scale and Locus of Control (LOC) scale were included in this research since previous studies reflected their impact on addiction. These two were Barron's Ego strength scale [32] and Rotter's Locus of Control [33].

Ego strength refers to an individual's conviction strength and self-regulation skills [34]. Individuals who have higher ego strength are expected to resist impulses and follow their conviction more than people with lower ego strength [35]. On the other hand, Locus of Control is the extent to which a person perceives that consequences are the results of his or her own behavior instead of outside forces that may occur independent of his or her own action [36]. Locus of Control in an individual could be conceptualized either internally or externally [37]. With the internal concept of LC, people believe that they have control over their lives and with the external concept, they believe that their acts and decisions are controlled by factors like environment, fate, chance, etc. which they have no control over [38]. This perception is not like none or all and could be varied in the degree that an individual believes in the role of internal and external forces. The reason behind including ego strength and LOC scales to this study was their impact on addiction as presented by previous studies [39]-[42].

As well, demographic information like gender, age, level of education ((under/post)graduate), citizenship (Malaysian/ non-Malaysian), level of income and SNS usage per a day were included in the questionnaire.

\section{RESULTS}

TABLE I: RATIO AND THE NUMBER OF FACEBOOK ADDICTION AMONG STUDENTS BASED ON DIFFERENT CATEGORIES

\begin{tabular}{|c|c|c|c|}
\hline & & Total & Ratio \\
\hline \multirow[t]{5}{*}{ Age } & $<=20$ & 98 & $57 \%$ \\
\hline & $(20-22]$ & 107 & $51 \%$ \\
\hline & $(22-25]$ & 81 & $35 \%$ \\
\hline & $(25-29]$ & 81 & $38 \%$ \\
\hline & $>29$ & 74 & $49 \%$ \\
\hline \multirow[t]{2}{*}{ Gender } & Male & 224 & $48 \%$ \\
\hline & Female & 217 & $45 \%$ \\
\hline \multirow[t]{2}{*}{ Religion } & Muslim & 364 & $49 \%$ \\
\hline & Non-Muslim & 77 & $36 \%$ \\
\hline \multirow[t]{2}{*}{ Citizenship } & Malaysian & 296 & $47 \%$ \\
\hline & Non-Malaysian & 145 & $46 \%$ \\
\hline \multirow[t]{2}{*}{ Level of Education } & Undergraduate & 257 & $50 \%$ \\
\hline & Postgraduate & 184 & $42 \%$ \\
\hline \multirow[t]{6}{*}{ SNS Hour Daily } & Less than 1 hour & 39 & $28 \%$ \\
\hline & [30 min - 1 hour) & 100 & $35 \%$ \\
\hline & [1-3) hours & 141 & $51 \%$ \\
\hline & [3-4) hours & 74 & $47 \%$ \\
\hline & [4-5) hours & 31 & $58 \%$ \\
\hline & $7<$ hours & 54 & $65 \%$ \\
\hline \multirow[t]{2}{*}{ Years Using SNSs } & Less than 4 & 171 & $42 \%$ \\
\hline & 4 and more & 269 & $51 \%$ \\
\hline \multirow{4}{*}{$\begin{array}{l}\text { Level OF Income } \\
(\mathrm{RM})\end{array}$} & Less than 1000 & 284 & $51 \%$ \\
\hline & $1000-2000$ & 76 & $37 \%$ \\
\hline & More than 2000 & 38 & $34 \%$ \\
\hline & Low & 109 & $45 \%$ \\
\hline \multirow[t]{3}{*}{ Ego Strength } & Medium & 69 & $49 \%$ \\
\hline & High & 28 & $47 \%$ \\
\hline & Low & 52 & $40 \%$ \\
\hline \multirow[t]{2}{*}{ Locus of Control } & Medium & 136 & $50 \%$ \\
\hline & High & 18 & $46 \%$ \\
\hline Total $(N=441)$ & & 206 & $47 \%$ \\
\hline
\end{tabular}

As suggested by BFAS developers [17], polythetic scoring scheme was used to determine the Facebook addicts in the sample. This scheme suggests those who answer 3 or above 
on at least four of the six items are Facebook addicts. Based on this scheme, 206 out of 441 cases were Facebook addicts which reflect a high ratio of $47 \%$ among the studied sample. Table I summarizes the ratio and number of Facebook addicts based on different characteristics of respondents.

As presented in Table I, the highest ratio of addicts in different categories of age was observed among students younger than 20 years old $(57 \%)$. However, it seems that Facebook addiction is not related to gender since the ratio of addicts among both males and females are approximately the same (respectively $48 \%$ and $45 \%$ ). In case of religion, a difference could be observed which might have been caused by the distribution differences among the respondents' religion (364 Muslims and 77 non-Muslims including Christians, Buddhist, Hindu, etc.). Malaysian Citizenship, education and history of using SNSs in addition to ego strength and locus of control seem to have the same ratio among different categories. Just like religion, level of income also reflects some difference among the different classes which might be due to sampling errors. The only factor that reflects a considerable change in different categories is the SNS online hours per day.

TABLE II: ANALYSIS OF VARIANCE MODEL FOR FACEBOOK ADDICTION RESULTS

\begin{tabular}{|c|c|c|c|c|c|}
\hline Source & $\begin{array}{l}\text { Type III } \\
\text { Sum of } \\
\text { Squares }\end{array}$ & $d f$ & $\begin{array}{l}\text { Mean } \\
\text { Square }\end{array}$ & $F$ & Sig. \\
\hline Corrected Model & $58.298^{\mathrm{a}}$ & 30 & 1.943 & 2.101 & .001 \\
\hline Intercept & .745 & 1 & .745 & .805 & .370 \\
\hline Age & .082 & 1 & .082 & .089 & .765 \\
\hline Gender & .127 & 1 & .127 & .138 & .711 \\
\hline Religion & 1.286 & 4 & .321 & .348 & .846 \\
\hline Citizenship & .093 & 1 & .093 & .101 & .751 \\
\hline $\begin{array}{l}\text { Level of } \\
\text { Education }\end{array}$ & .270 & 1 & .270 & .292 & .589 \\
\hline SNS Hours Daily & 27.591 & 6 & 4.599 & 4.972 & .000 \\
\hline Years Using SNS & 3.533 & 5 & .707 & .764 & .576 \\
\hline $\begin{array}{l}\text { Level of Income } \\
(\mathrm{RM})\end{array}$ & 9.549 & 7 & 1.364 & 1.475 & .175 \\
\hline Ego Strength & 2.487 & 2 & 1.244 & 1.344 & .262 \\
\hline Locus of Control & 2.459 & 2 & 1.229 & 1.329 & .266 \\
\hline Error & 355.193 & 384 & .925 & & \\
\hline Total & 413.498 & 415 & & & \\
\hline Corrected Total & 413.491 & 414 & & & \\
\hline \multicolumn{6}{|c|}{ a. R Squared $=.141($ Adjusted R Squared $=.074)$} \\
\hline
\end{tabular}

Across different groups, an incremental ratio of addicts is observed which means that the more SNS usage per a day, the more the ration of addicts. It is a conceptually sound observation since addicts need to use more, and they theoretically should spend more time surfing their Facebook pages. To test whether any significant difference is observed among different groups of respondents, addiction score was calculated using Factor Analysis based on the 6 items of BFAS. Having the addiction scores, analysis of variance model was applied to investigate the effect of these factors on addiction. Table II reflects the results of this test in this study.

Taking Sig<0.05 as a significant difference, the only considerable amount was observed on daily hours spent on SNSs. The remaining factors did not reflect any significance in the Facebook addiction. In addition, tests were repeated employing logistic regression by categorizing original addiction score into two groups, addicts and not-addicts, using both conservative (scoring 3 or above on all six items) and liberal scoring (same as what is done in current research) as suggested by Andreseassen et al. [17]. All of these tests were repeatedly performed with different sets of categories for ego strength, locus of control and age. Similarly, none of these attempts reflected any difference and the only significant difference belonged to hours spent on SNSs. These results suggest that SNS addiction is not related to any of aforementioned factors and the chance of people being addicted to Facebook is almost the same in different categories.

\section{CONCLUSION}

According to the findings of this study, $47 \%$ of the survey respondents could be considered as Facebook addicts. Despite other researches that reflected a considerable difference among Facebook addicts' gender, (e.g. [43]), in current sample, no significant difference was observed based on respondents' gender. This was the same for other investigated variables, including age, religion, citizenship, level of education, number of years they were using SNSs, level of income, ego strength and locus of control. The only considerable difference was observed in the hours spent on Facebook and other SNSs daily. This could reflect a unique characteristic of Facebook addiction, which needs more investigation.

In addition, Future studies can focus more on other aspects of Facebook addiction. For instance, with easy access to the internet and the existence of smart phones, people have access to SNSs any time, any place. But, the unmanageable use of Facebook may have some impact on their ability to fulfill their responsibilities or communicate with real friends. In future studies, more can be done on the extreme usage of Facebook and other SNSs and the issues that may arise due to this addiction.

\section{ACKNOWLEDGMENT}

This work is supported by the Fundamental Research Grant Scheme (FRGS) of Ministry of Higher Education (MOHE), Malaysia with reference to FRGS/1/2014/ICT01/UTM/02/2 (Vot: 4F441). Universiti Teknologi Malaysia (UTM) is gratefully acknowledged for its Research University Grant (Vot: 07J79). The authors would like to thank Dr Zohreh Toghrayee for her help with data analysis.

\section{REFERENCES}

[1] F. Sabatini and F. Sarracino, "Online networks and subjective well-being," Online Networks and Subjective Well-Being, Working Paper, pp. 1-40, 2014.

[2] B. McCord, T. L. Rodebaugh, and C. A. Levinson, "Facebook: Social uses and anxiety," Computers in Human Behavior, vol. 34, pp. 23-27, May, 2014. 
[3] L. D. Rosen, K. Whaling, S. Rab, L. M. Carrier, and N. A. Cheever, "Is Facebook creating 'iDisorders'? The link between clinical symptoms of psychiatric disorders and technology use, attitudes and anxiety," Computers in Human Behavior, vol. 29, no. 3, pp. 1243-1254, 2013.

[4] J. Kim and P. M. Haridakis, "The role of internet user characteristics and motives in explaining three dimensions of internet addiction," Journal of Computer-Mediated Communication, vol. 14, no. 4, pp 988-1015, 2009.

[5] S. Byun, C. Ruffini et al., "Internet addiction: Metasynthesis of 1996-2006 quantitative research," Cyber Psychology \& Behavior, vol. 12, no. 2, pp. 203-207, 2009.

[6] D. Hinić, G. Mihajlović, Ž. Špirić, S. Đukić-Dejanović, and M. Jovanović, "Excessive internet use: Addiction disorder or not?" Vojnosanitetski Pregled, vol. 65, no. 10, pp. 763-767, 2008.

[7] O. Turel, A. Serenko, and P. Giles, "Integrating technology addiction and use: an empirical investigation of online auction users," MIS Quarterly, vol. 35, no. 4, pp. 1043-1062, 2011.

[8] H. Xiuqin, Z. Huimin, L. Mengchen, W. Jinan, Z. Ying, and T. Ran, "Mental health, personality, and parental rearing styles of adolescents with Internet addiction disorder," Cybersychology, Behavior, and Social Networking, vol. 13, no. 4, pp. 401-406, 2010.

[9] W. K. Park, "Mobile phone addiction," in Mobile Communications: Re-negotiation of Social Sphere, D. Diaper and C. Sanger, Eds., London, UK: Springer, 2005, vol. 1, pp. 253-272.

[10] M. Griffiths, "Sex on the internet: Observations and implications for internet sex addiction," The Journal of Sex Research, vol. 38, pp. 333-342, Nov. 2001.

[11] K. S. Young, "Internet sex addiction risk factors, stages of development, and treatment," American Behavioral Scientist, vol. 52, no. 1, pp. 21-37, 2008.

[12] M. D. Griffiths and N. Hunt, "Dependence on computer games by adolescents," Psychological Reports, vol. 82, no. 2, pp. 475-480, 1998.

[13] C. Flisher, "Getting plugged in: An overview of Internet addiction," Journal of Paediatrics and Child Health, vol. 46, no. 10, pp. 557-559, 2010.

[14] K. S. Young, "Internet addiction: The emergence of a new clinical disorder," Cyber Psychology \& Behavior, vol. 1, no. 3, pp. 237-244, 1998.

[15] D. J. Kuss and M. D. Griffiths, "Online social networking and addiction - A review of the psychological literature," International Journal of Environmental Research and Public Health, vol. 8, no. 9, pp. 3528-3552, 2011.

[16] N. Mahadi. (2013). 13.3 million M'sians are Facebook users. [Online]. Available:

http://www.theborneopost.com/2013/06/16/13-3-million-msians-are-f acebook-users/

[17] C. S. Andreassen, T. Torsheim, G. S. Brunborg, and S. Pallesen, "Development of a Facebook addiction scale," Psychological Reports, vol. 110, no. 2, pp. 501-517, 2012.

[18] Oxford, Oxford American Wordpower Dictionary, 1st ed., vol. 1, New Yourk: Oxford University Press, 1998.

[19] J. Reiman, Critical Moral Liberalism: Theory and Practice, vol. 70, United States of America Rowman \& Littlefield, 1997.

[20] I. Kant, Lectures on Ethics, 1st ed., vol. 1, United States of America: The Press Syndicate of the University of Cambridge, 1997.

[21] M. A. Shotton, Computer Addiction Dependency: A Study of Computer Dependency, vol. 1. London: Taylor \& Francis, 2004.

[22] J. Weizenbaum and J. McCarthy, "Computer power and human reason: From judgment to calculation," Physics Today, vol. 30, no. 1, p. 68, 1977.

[23] H. J. Shaffer, M. N. Hall, and J. V. Bilt, "Computer addiction: A critical consideration," American Journal of Orthopsychiatry, vol. 70, no. 2 , pp. 162-168, 2000.

[24] K. S. Young, "Internet addiction: symptoms, evaluation and treatment," Innovations in Clinical Practice: A Source Book, vol. 17, pp. 19-31, 1999.

[25] M. A. Shotton, "The costs and benefits of 'computer addiction'," Behaviour \& Information Technology, vol. 10, pp. 219-230, May 1991.

[26] R. Pies, "Should DSM-V designate 'Internet addiction' a mental disorder?" Psychiatry (Edgmont), vol. 6, p. 31, 2009.

[27] J. Block, "Issues for DSM-V: Internet addiction," American Journal of Psychiatry, vol. 165, no. 3, pp. 306-307, 2008.

[28] A. Kapahi, C. S. Ling, S. Ramadass, and N. Abdullah, "Internet addiction in Malaysia causes and effects," I-Business, vol. 5, no. 2, pp. 72-76, 2013.
[29] B. T. Haghighi, M. Othman, and F. H. Hashim, "Internet addiction and dependency: A case study in UNITEN, Malaysia," presented at the ICIM 2011, Kuala Lumpur, Nov. 14-16, 2011.

[30] R. Brown, "Some contributions of the study of gambling to the study of other addictions," in Gambling Behavior and Problem Gambling, W. R. Eadington and J. A. Cornelius, Eds., vol. 1, Reno, Nevada: University of Nevada, 1993, pp. 241-272.

[31] M. Griffiths, "Nicotine, tobacco and addiction," Nature, vol. 384, p. 18, 1996.

[32] F. Barron, "An ego-strength scale which predicts response to psychotherapy," Journal of Consulting Psychology, vol. 17, no. 5, p. 327,1953 .

[33] J. B. Rotter, "Generalized expectamcies for internal versus external control of reinforcement " Psychological Monographs: General and Applied, vol. 80, no. 1, pp. 1-28, 1966.

[34] L. N. K. Leonard, T. P. Cronan, and J. Kreie, "What influences IT ethical behavior intentions planned behavior, reasoned action, perceived importance, or individual characteristics?" Information \&amp; Management, vol. 42, no. 1, pp. 143-158, 2004.

[35] D. Banerjee, T. P. Cronan, and T. W. Jones, "Modeling IT ethics: a study in situational ethics," MIS Quarterly, vol. 22, no. 1, pp. 31-60, 1998.

[36] J. B. Rotter, "Generalized expectancies for internal versus external control of reinforcement," Psychological Monographs: General and Applied, vol. 80, no. 1, pp. 1-28, 1966.

[37] J. B. Rotter, "Internal versus external control of reinforcement," American Psychologist, vol. 45, no. 4, pp. 489-493, 1990.

[38] M. B. Kormanik and T. S. Rocco, "Internal versus external control of reinforcement: a review of the locus of control construct," Human Resource Development Review, vol. 8, pp. 463-483, December 1, 2009.

[39] K. Chak and L. Leung, "Shyness and locus of control as predictors of internet addiction and internet use," Cyber Psychology \& Behavior vol. 7, no. 5, pp. 559-570, 2004.

[40] M. İskender and A. Akin, "Social self-efficacy, academic locus of control, and internet addiction," Computers \& Education, vol. 54, no. 4, pp. 1101-1106, 2010.

[41] R.-M. Shepherd and R. J. Edelmann, "Reasons for internet use and social anxiety," Personality and Individual Differences, vol. 39, pp. 949-958, 2005.

[42] J. L. Barbieri, "The URGES approach: Urge reduction by growing ego strength (URGES) for trauma/addiction treatment using alternate bilateral stimulation, hypnotherapy, ego state therapy and energy psychology," Sexual addiction \& compulsivity, vol. 15, no. 2, pp 116-138, 2008.

[43] S. Balci and A. Glcü, "Facebook addiction among university students in Turkey: Selcuk University example," Journal of Turkish Studies, issue 34, p. 24, Nov. 2013

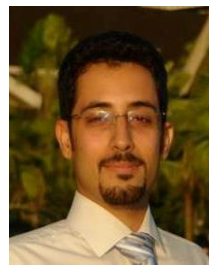

Hosein Jafarkarimi earned his master's degree in information teknology management from Universit Teknologi Malaysia in 2011. He is now an information systems $\mathrm{PhD}$ candidate in Universiti Teknologi Malaysia and a member of the ISSI research group in UTM's Faculty of Computing. His field of interests include computer ethics, behavioral studies and data mining. He is a member of Faculty in Islamic Azad University Damavand in Iran.

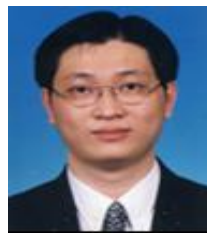

Alex Tze Hiang Sim received his $\mathrm{PhD}$ degree from Monash University, Australia. He was working as a business \& program analyst for six years after graduated from his first degree. He was then attached to the Department of Information Systems at Universiti Teknologi Malaysia (UTM) as a senior lecturer. He has been teaching courses such as data mining, research methods and databases. His research interest is in data mining and its applications. He has supervised more than twenty international $\mathrm{PhD}$ and master students. He is currently a member of AIS, IEEE and ACM. 


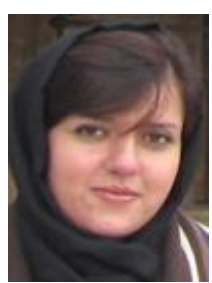

Robab Saadatdoost received the B.E. degree in software engineering from the University of Kharazmi, Iran, in 2005, and the master degree in information technology management from Universiti Teknologi Malaysia in 2011. She is a PhD student in information systems in Universiti Teknologi Malaysia. In 2009, she joined the Department of Information Systems, Universiti Teknologi Malaysia, as a student. Her curren research interests include educational technologies, cloud computing, qualitative researches and data mining / knowledge discovery process. She was the recipient of the Malaysia International Scholarship (MIS) in 2011.

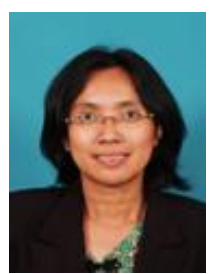

Hee Jee Mei is a senior lecturer at the Faculty of Education, Universiti Teknologi Malaysia which is located at the southern part of Peninsular Malaysia. She has been serving the university since year 1998. She received her $\mathrm{PhD}$ from Deakin University, Australia, majoring in online, flexible and distance education. She has been teaching courses such as educational research methodology, assessment and evaluation, pedagogy, and curriculum development. Her research interest is in e-learning and online assessment. 